\title{
PERHITUNGAN KAPASITAS DRAINASE UNTUK MENGATASI PERMASALAHAN GENANGAN AIR DI JALAN RAYA CIBABAT (JALAN NASIONAL 3) KAMPUNG KARANG MEKAR KECAMATAN CIMAHI UTARA
}

\author{
Farah Fauziah, Lailatul MaghfirohTsaniah Putu, Mutioro Sukmono, Iin Karnisah \\ Jurusan Teknik Sipil Politeknik Negeri B andung, Bandung 40012 \\ E-mail:fafarahyoachmadi@gmail.com
}

\begin{abstract}
ABSTRAK
Daerah Cimahi yang sering mengalami genangan air yaitu daerah di Jalan Raya Cibabat (Jalan Nasional 3) yang terletak di Kampung Karang Mekar, Kelurahan Cibabat, Kecamatan Cimahi Utara. Salah satu penyebab terjadinya genangan yaitu kondisi lahan, dimana terjadi cekungan pada daerah tersebut. Selain itu penyebab terjadi genangan air yaitu kapasitas drainase di daerah tinjauan yang sudah tidak me madai dan tersumbatnya saluran oleh sampah.

Pada penelitian ini dilakukan pemeriksaan kapasitas drainase baru dengan metode analisis hidrologi secara manual dan analis is hidrolika dengan dua cara yaitu manual dan menggunakan Software HEC-RAS. Pengumpulan data didapatkan dari hasil survei lapangan dan data sekunder seperti data curah hujan didapat dari PU pengairan, dan data citra satelit. Hasil analis is penampang eksisting didapatkan bahwa kapasitas drainase pada saluran S.D-C dan S.C-E masih mampu untuk menahan debit hujan rencana sampai 10 tahun kedepan, sedangkan drainase pada saluran S.E-F, S.F-G dan outlet sudah tidak memadai. Maka dari itu solusi untuk mengatasi genangan air di saluran S.E-F, S.F-G dan outlet yaitu normalisasi dengan memperbesar dimensi drainase dengan ukuran $1.5 \mathrm{~m} \times 1.5 \mathrm{~m}$ di saluran S.E-F, ukuran $2.3 \mathrm{~m}$ x $2.3 \mathrm{~m}$ di S.F-G dan 2,5 m x 2,5 pada saluran outlet.
\end{abstract}

\section{Kata kunci:}

Kapasitas Drainase, Analis is Hidrolika, Analis is Hidrologi, Software HEC-RAS, Normalisasi.

\section{PENDAHULUAN}

\subsection{LatarBelakang}

Jalan Raya Cibabat (Jalan Nasional 3) terletak di Kampung Karang Mekar, Kelurahan Cibabat, Kecamatan Cimahi Utara adalah salah satu daerah yang sering dilanda banjir. Jalan Raya Cibabat terletak diantara Jalan A mir Mahmud (dari arah Bandung) dan Jalan Daeng Moh. Ardiwinata dari arah Cihanjuang dimana elevasi Jalan Raya Cibabat lebih rendah daripada kedua jalan tersebut [1]. Kondisi ini menyebabkan terjadinya genangan di daerah tersebut. Selain elevasi, diprediksi genangan air yang terjadi disebabkan oleh kapasitas drainase yang berada di Jalan Raya Cibabat sudah tidak memadai ditambah dengan saluran di Jalan Raya Cibabat sudah tidak mampu menampung limpasan air yang berasal dari air hujan dan air limbah yang berada di daerah tersebut [2].

\subsection{Tujuan}

Tujuan penelitian ini adalah sebagai berikut:

1. Menghitung kapasitas drainase yang sesuai berdasarkan debit banjir rencana.

2. Merumuskan solusi untuk mengatasi permasalahan genangan yang ada di Jalan Raya Cibabat (Jalan Nasional 3) Kampung Karang Mekar Kecamatan Cimahi Utara.

\section{METODE}

Metodologi yang digunakan untuk mengatasi genangan air di Jalan Raya Cibabat dapat dilihat pada Gambar 1. 


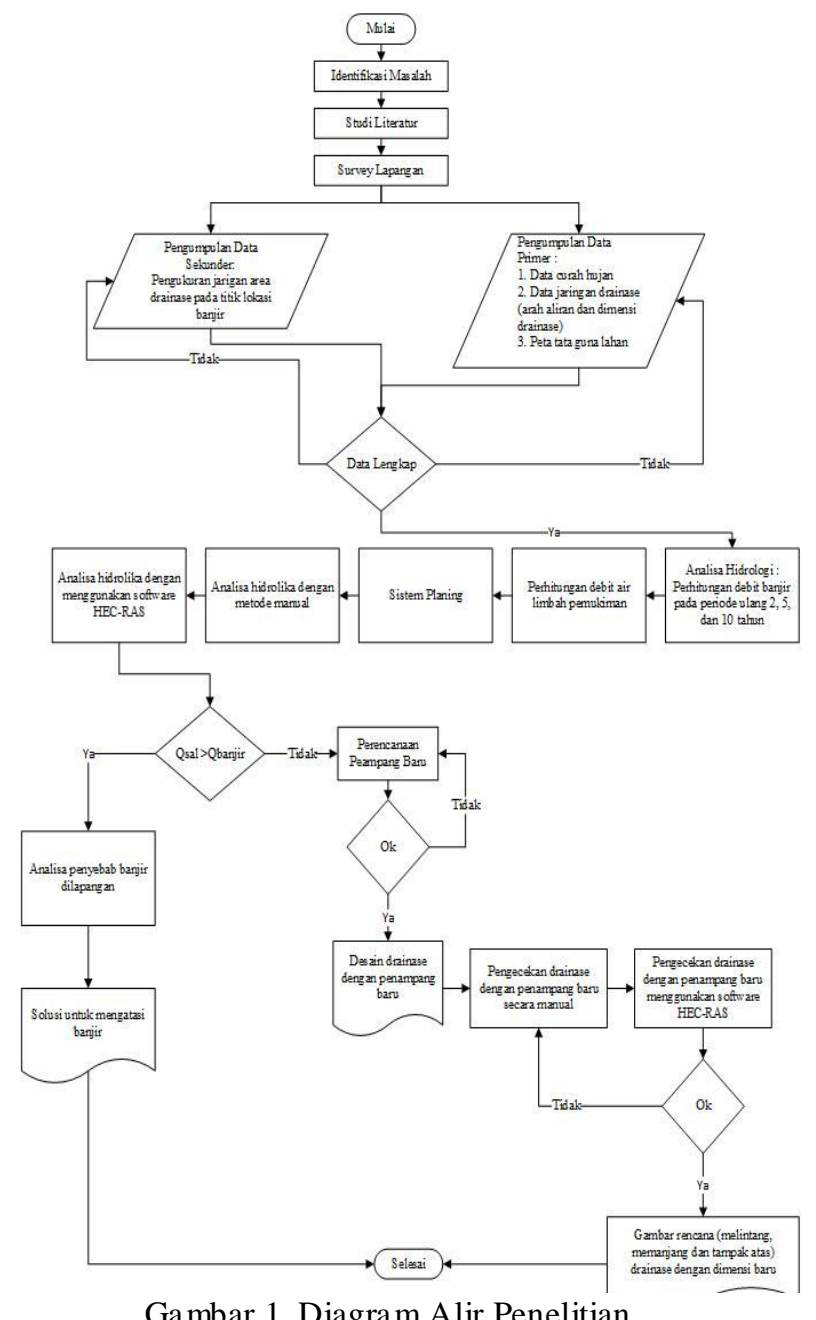

Gambar 1. Diagram Alir Penelitian

\subsection{Identifikasi Masalah}

Identifikasi masalah adalah langkah pertama untuk mengetahui permasalahan yang terjadi pada tugas akhir ini. Dalam mengidentifikasi masalah yang dilakukan adalah dengan cara survei keadaan drainase di Jalan Raya Cibabat (Jalan Nasional 3) Kampung Karang Mekar Kecamatan Cimahi Utara, mencari data tentang data banjir yang terjadi beberapa tahun kebelakang.

\subsection{Studi Literatur}

Melakukan pencarian referensi yang terkait dengan mencari kapasitas drainase dan solusi apa saja yang dapat dilaku kan untuk menanggulangi genangan yang terjadi di Jalan Raya Cibabat (Jalan Nasional 3) Kampung Karang Mekar Kecamatan Cimahi Utara.

\subsection{Pengumpulan Data}

Pengumpulan data dilakukan dengan dua macam data yaitu data sekunder dan data primer. Data primer yaitu data yang didapat dengan melakukan survey langsung dilapangan. Sedangkan data sekunder adalah data yang didapatkan dari Pemerintah Kota Cimahi dan Badan Pusat Statistik [3].

\subsection{Analisis Hidrologi}

Dalam analisis hidrologi ini yaitu melakukan analisis data curah hujan, analisis curah hujan ratarata, analisis debit banjir, dan analisis debit air limbah pemukiman warga. Analisis ini dilakukan dengan metode rasional pada periode ulang tertentu. Output dari analisis hidrologi ini mendapatkan debit total dari debit curah hujan dan debit air limbah pemukiman warga di Jalan Raya Cibabat (Jalan Nasional 3) Kampung Karang Mekar Kecamatan Cimahi Utara dan debit banjir dari air limbah pemukiman. Bagan alir dari analisis hidrologi dapat dilihat pada Gambar 2.

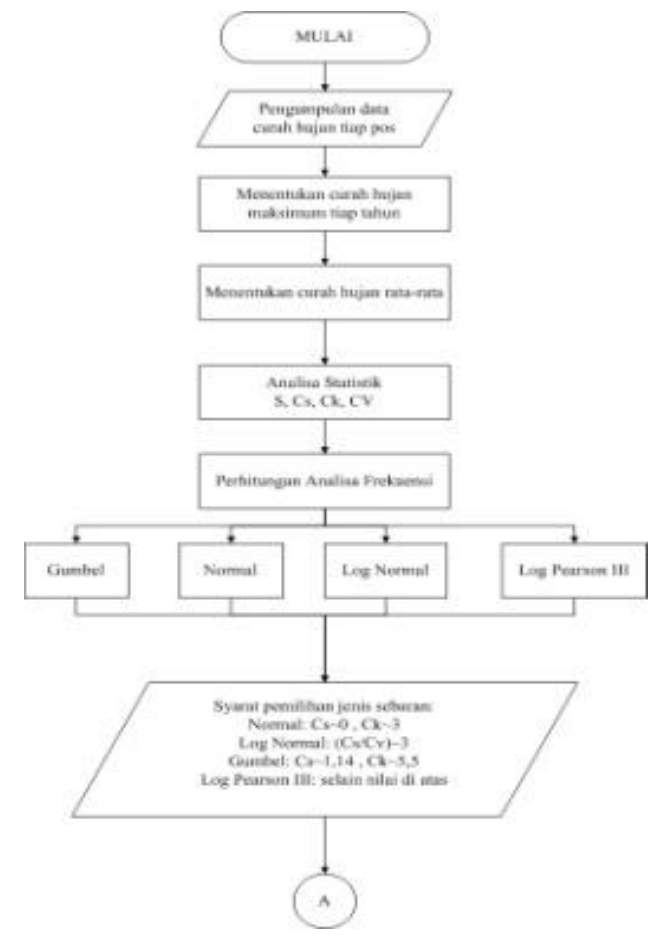

PERHITUNGAN KAPASITAS DRAINASE UNTUK MENGATASI PERMASALAHANGENANGAN AIR 


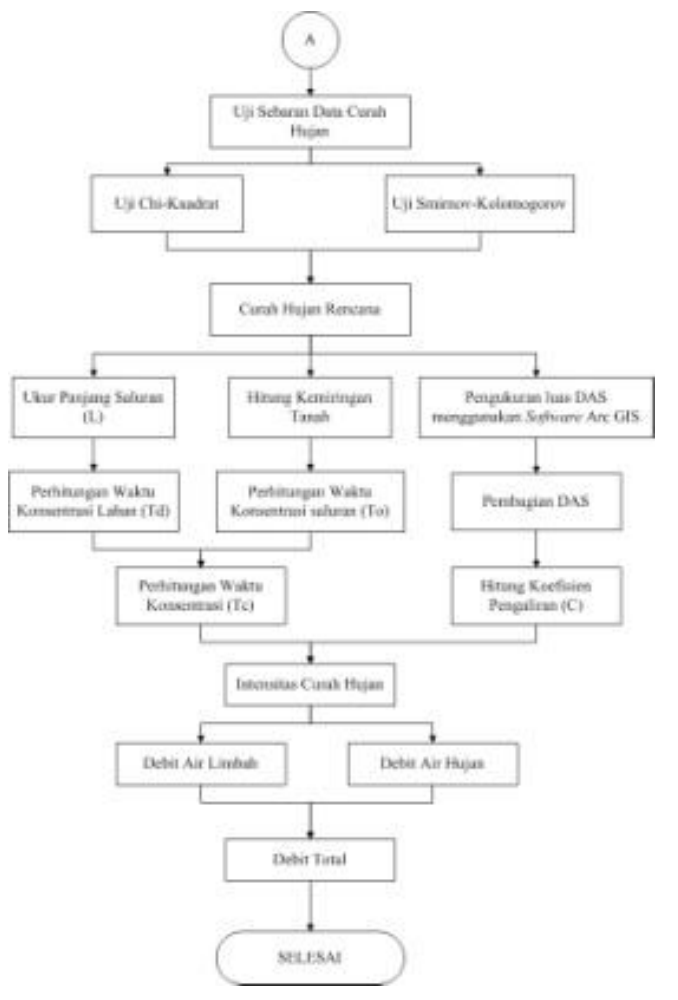

Gambar 2. Bagan Alir Analisis Hidrologi

\subsection{Analisis Hidrolika}

Analisis hidrolika dilakukan untuk menghitung kapasitas drainase dengan cara manual. Output dari analisis hidrolika ini yaitu mengetahui kapasitas drainase dan tinggi luapan yang terjadi pada drainase tersebut. Berikut adalah bagan alir dari analisis hidrolika dapat dilihat pada Gambar 3.

\subsection{Analisis Hidrolika Menggunakan Software HEC-RAS}

Selain menganalisis hidrolika secara manual dilakukan pula menganalisis dengan Software HEC-RAS. Berikut adalah alir untuk melakukan analisis dengan Software HEC-RAS dapat dilihat di Gambar 4.

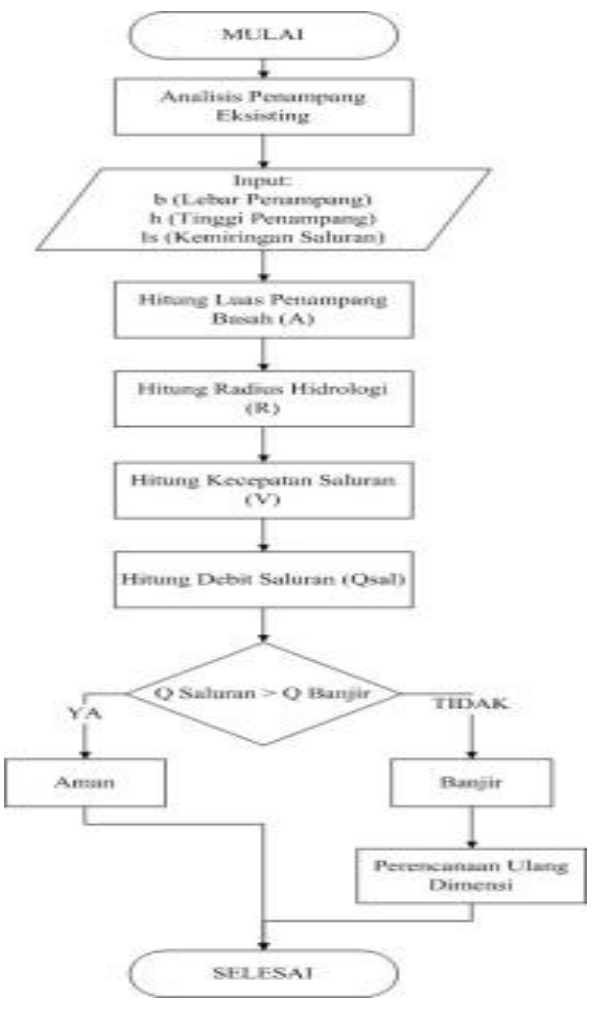

Gambar 3. Bagan Alir Analisis Hidro lika

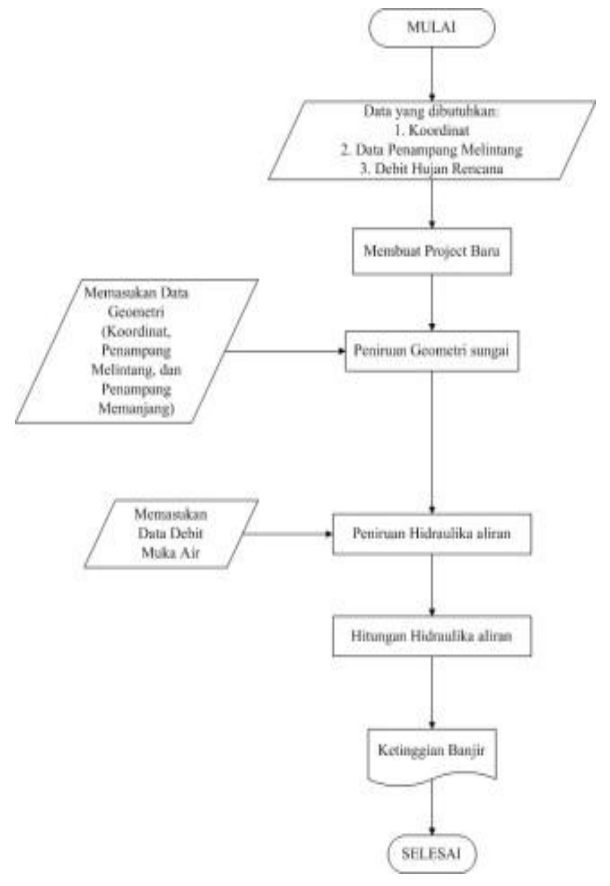

Gambar 4. Bagan Alir Analisis Hidrolika menggunakan software HEC-RA S

PERHITUNGAN KAPASITAS DRAINASE UNTUK MENGATASI PERMASALAHANGENANGAN AIR

D JALAN RAYA CIBABAT (JALAN NASIONAL 3) KAMP UNG KARANG MEKAR KECAMATAN CIMAHI UTARA

Farah Fauziah, Lailatul Maghfiroh Tsaniah Putu, Mutioro Sukmono, Iin Karnisah 


\subsection{Rencana Penanggulangan Genangan}

Salah satu cara penanggulangan genangan adalah normalisasi. Normalisasi adalah kegiatan untuk memperbaiki saluran dan sarana drainase lainnya termasuk bangunan pelengkap sesuai dengan kriteria perencanaan [3]. Normalisasi drainase yang dimaksud adalah perencanaan penampang dengan hasil akhir yaitu desain penampang baru serta gambar potongan memanjang dan melintang saluran drainase yang telah direncanakan ulang.

\section{HAS IL DAN ANALIS IS}

\subsection{Analisis Hidrologi}

Hasil dari analisis Hidrologi ini adalah debit banjir rencana dimana debit banjir rencana ini merupakan debit total dari debit air hujan yang dihitung dengan metode rasional dan debit air limbah. Hasil analis is hidrologi dapat dilihat pada tabel berikut.

Tabel 1. Hasil Analis is Hidrologi

\begin{tabular}{|c|c|c|c|c|}
\hline \multirow{2}{*}{ No } & \multirow{2}{*}{ Nama Saluran } & \multicolumn{3}{|c|}{$\begin{array}{c}\text { BanjirRencana } \\
\left(\mathrm{m}^{3} / \text { detik }\right)\end{array}$} \\
\cline { 3 - 5 } & & $\mathrm{Q}_{2 \mathrm{~h}}$ & $\mathrm{Q}_{5 \mathrm{th}}$ & $\mathrm{Q}_{10 \mathrm{th}}$ \\
\hline 1 & \multirow{2}{*}{ S.A-B } & $\begin{array}{c}0.730 \\
4\end{array}$ & $\begin{array}{c}0.843 \\
4\end{array}$ & $\begin{array}{c}0.918 \\
2\end{array}$ \\
\hline 2 & S.B.C & $\begin{array}{c}0.716 \\
4\end{array}$ & $\begin{array}{c}0.827 \\
1\end{array}$ & $\begin{array}{c}0.900 \\
5\end{array}$ \\
\hline 3 & S.D-C & $\begin{array}{c}0.692 \\
9\end{array}$ & $\begin{array}{c}0.800 \\
0\end{array}$ & $\begin{array}{c}0.871 \\
0\end{array}$ \\
\hline 4 & S.C-E & $\begin{array}{c}1.392 \\
6\end{array}$ & $\begin{array}{c}1.607 \\
7\end{array}$ & $\begin{array}{c}1.750 \\
3\end{array}$ \\
\hline 5 & S.B-F & $\begin{array}{c}1.027 \\
7\end{array}$ & $\begin{array}{c}1.186 \\
5\end{array}$ & $\begin{array}{c}1.291 \\
8\end{array}$ \\
\hline 6 & S.E-F & $\begin{array}{c}1.320 \\
5\end{array}$ & $\begin{array}{c}1.524 \\
4\end{array}$ & $\begin{array}{c}1.659 \\
6\end{array}$ \\
\hline 7 & S.G-F & $\begin{array}{c}3.196 \\
6\end{array}$ & $\begin{array}{c}3.690 \\
9\end{array}$ & $\begin{array}{c}4.018 \\
3\end{array}$ \\
\hline 8 & OUTLET & $\begin{array}{c}4.517 \\
1\end{array}$ & $\begin{array}{c}5.215 \\
3\end{array}$ & $\begin{array}{c}5.678 \\
0\end{array}$ \\
\hline
\end{tabular}

\subsection{Analisis Hidrolika}

Analisis hidrolika ini dilakukan untuk mengetahui kondisi saluran apakah mampu menampung debit banjir rencana atau tidak. Jika penampang eksisting sudah tidak memadai maka perlu dilakukan perencanaan ulang terhadap penampang eksisting yang disesuaikan dengan debit banjir rencana. Pada penelitian ini analisis hidrolika dilakukan pada saluran sekunder.
Hasil dari analisis hidrolika menggunakan metode manual [dapat dilihat pada tabel berikut.

Tabel 2. Hasil Analis is Hidrolika

\begin{tabular}{|c|c|c|c|c|c|}
\hline Saluran & $\mathrm{b}(\mathrm{m})$ & $\mathrm{h}(\mathrm{m})$ & Qsal & $\mathrm{Q}_{\text {2th }}$ & Ket \\
\hline S.D-C & 0.7 & 0.94 & 1.9 & 0.7 & Aman \\
\hline S.C-E & 0.7 & 0.9 & 1.9 & 1.4 & Aman \\
\hline S.E-F & 0.5 & 0.45 & 0.3 & 1.3 & Banjir \\
\hline S.G-F & 0.7 & 0.94 & 1.2 & 3.2 & Banjir \\
\hline OUTLET & 0.7 & 0.94 & 2.1 & 4.5 & Banjir \\
\hline
\end{tabular}

Tabel 3. Hasil Analisis Hidrolika (Lanjutan)

\begin{tabular}{|c|c|c|c|c|}
\hline Saluran & $\mathrm{Q}_{\text {5th }}$ & Ket & $\mathrm{Q}_{10 \text { th }}$ & Ket \\
\hline S.D-C & 0.8 & Aman & 0.9 & Aman \\
\hline S.C-E & 1.6 & Aman & 1.8 & Aman \\
\hline S.E-F & 1.5 & Banjir & 1.7 & Banjir \\
\hline S.G-F & 3.7 & Banjir & 4.0 & Banjir \\
\hline OUTLET & 5.2 & Banjir & 5.7 & Banjir \\
\hline
\end{tabular}

\subsection{Analisis Hidrolika Menggunakan Software HEC-RAS}

Hasil dari analisis hidrolika menggunakan software HEC-RAS dapat dilihat pada ga mbar berikut.

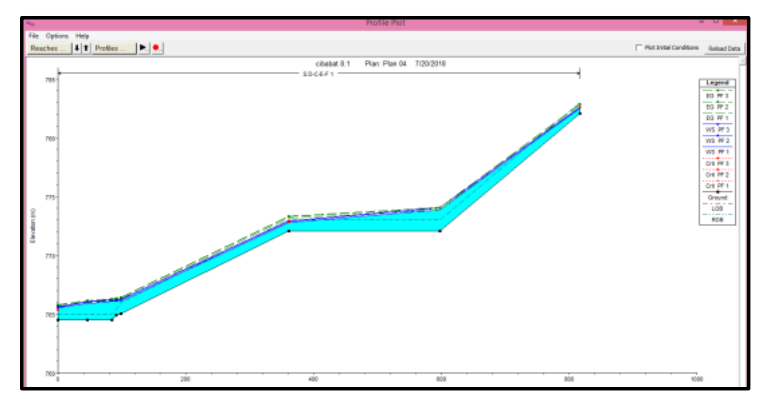

Gambar 5. Potongan Memanjang

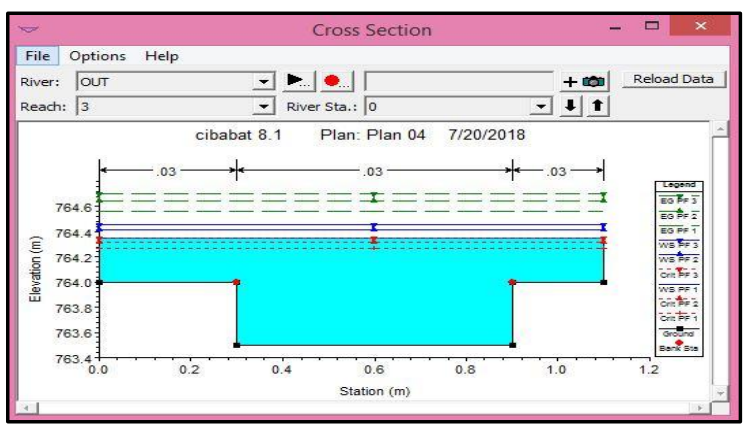

Gambar 6. Potongan Melintang 


\subsection{Perencanaan Penampang Baru}

Setelah melakukan pengecekan terhadap kapasitas drainase secara manual dan HEC-RAS didapatkan bahwa kapasitas drainase sesudah tidak bisa menampung debit banjir rencana. Maka dari itu diperlukan dimensi yang baru agar debit air dapat menampung debit banji rencana. Debit banjir rencana yang diambil yaitu pada periode 10 tahun, dikarenakan perencaaan drainase ini untuk 10 tahun kedepan.

Perencanaan dimensi drainase ini dilakukan pada saluran yang banjir yaitu pada saluran S.E-F, saluran S.G-F dan outlet. Saluran direncanakan menggunakan box culvert berbentuk persegi. Hasil perencanaan dimensi baru dilihat pada tabel berikut.

Tabel 4. Hasil Perencanaan Dimensi Baru

\begin{tabular}{|c|c|c|c|c|c|c|c|}
\hline \multirow{2}{*}{ Saluran } & \multirow{2}{*}{$\begin{array}{c}\mathrm{b} \\
(\mathrm{m})\end{array}$} & \multirow{2}{*}{$\begin{array}{c}\mathrm{H} \\
(\mathrm{m})\end{array}$} & \multirow{2}{*}{$\begin{array}{c}\text { W } \\
(\mathrm{m})\end{array}$} & \multirow{2}{*}{$\underset{(\mathrm{m})}{\mathrm{H}}$} & \multirow{2}{*}{$\begin{array}{c}\text { Box culvert } \\
\text { y ang } \\
\text { digunakan } \\
(\mathrm{m})\end{array}$} & \multicolumn{2}{|c|}{$\begin{array}{c}\text { Elevasi permukaan } \\
\text { tanggul }\end{array}$} \\
\hline & & & & & & $\mathrm{T} 1$ & $\mathrm{~T} 2$ \\
\hline S.E-F & 1.5 & 0.8 & 0.6 & 1.4 & $1.5 \times 1.5 \times 1$ & 765.15 & 765.00 \\
\hline S.G-F & 2.3 & 1.2 & 0.8 & 2.0 & $2.3 \times 2.3 \times 1$ & 765.09 & 765.00 \\
\hline OUTLET & 2.5 & 1.6 & 0.9 & 2.5 & $2.5 \times 2.5 \times 1$ & 763.91 & 763.90 \\
\hline
\end{tabular}

\subsection{Pengecekan Penampang Baru Menggunakan} Software HEC-RAS

Dimensi rencana baru dicek kembali menggunakan software HEC-RAS. Hasil pengecekan penampang baru dapat dilihat pada gambar berikut.

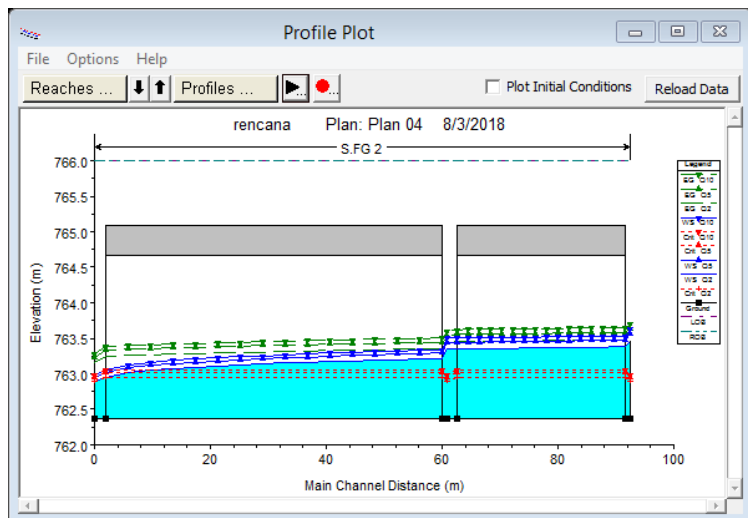

Gambar 6. Potongan Memanjang pada Saluran S.G-F

\section{KES IMPULAN DAN SARAN}

\subsection{Kesimpulan}

Dari analisis pada bab sebelumnya dapat disimpulkan sebagai berikut.
1. Debit banjir rencana yang digunakan terdiri dari debit air hujan dan debit air limbah. Karena daerah Cibabat memiliki sistem drainase tercampur.

2. Setelah dilakukan analisis hidrolika pada kondisi penampang eksisting, saluran S.E-F, S.F-G dan OUTLET sudah tidak mampu menahan debit banjir rencana.

3. Analisis kondisi eksisting saluran drainase secara manual hasilnya lebih besar dibandingkan dengan analisis kondisi eksisting menggunakan software HEC-RAS.

4. Pada saluran S.E-F, S.F-G, dan OUTLET dilakukan perencanaan ulang dengan perhitungan manual. Saluran yang direncanakan menggunakan box culvert. Untuk saluran S.E-F menggunakan box culvert dengan ukuran $1.5 \mathrm{~m} \times 1.5 \mathrm{~m}$, untuk saluran S.F-G menggunakan box culvert dengan ukuran $2.3 \mathrm{~m} \times 2.3 \mathrm{~m}$, sedangkan untuk saluran OUTLET menggunakan box culvert dengan ukuran $2.5 \times 2.5 \mathrm{~m}$.

\subsection{Saran}

Saran yang dapat dilakukan untuk mengatasi masalah genangan di Jalan Raya Cibabat adalah sebagai berikut.

1. Penampang yang sudah direncanakan dapat dijadikan rekomendasi untuk tindaklanjut perencanaan drainase di Jalan Raya Cibabat.

2. Perlu dilakukan edukasi pada masyarakat agar tidak membuang sampah pada saluran drainase.

\section{DAFTAR PUS TAKA}

[1] Farida, Meliawati dan Siti Nurbayti. 2017. Pembuatan Sistem Informasi Geografis Daerah Genangan pada Jaringan Drainase Jalan Wilayah Kota Cimahi Provinsi Jawa Barat. Bandung: Politeknik Negeri Bandung.

[2] Nurhasanah, Tri dan Wan S.M Faruq. 2016. Perancangan Ulang Drainase di Kawasan Perumnas Cijerah Melong Kota Cimahi. B andung: Jurusan Teknik Sipil, Politeknik Negeri Bandung.

[3] Badan Pusat Statistik Kota Cimahi. 2015. Jumlah Penduduk 2015. Cimahi: Badan Pusat Statistik Kota Cimahi.

[4] Djihad, Achmad. 2014. Hidrolika. Bandung: Politeknik Negeri Bandung. 